\title{
Guest Editorial: Understanding vulnerabilities in old age
}

Understanding vulnerability matters because being vulnerable represents a profoundly undesirable state. People who experience vulnerability in old age are of obvious humanitarian concern, as their insecurity and heightened exposure to certain threats is likely to be compounded by reduced capacities for coping independently. Comprehension of the causes and consequences of vulnerability is important for the development of social policies as it indicates ways of avoiding and alleviating bad outcomes. Policies which have the concept of vulnerability at their heart encourage the development of preventive and targeted measures, which is crucial in conditions of financial constraints and competing demands. By studying vulnerability we investigate processes of relative disadvantage or exclusion and, for purposes of comparison, absolute differences in socio-economic or policy context can be set aside. This makes the study of vulnerability particularly germane to cross-cultural and cross-national research on old-age and elderly support.

Comparative approaches are becoming not only increasingly relevant in a rapidly changing and globalising world, but also increasingly possible. For example, recognition of the challenges posed by extremely rapid age-structural transformations in Asia, or by the coincidence of ageing and HIV/AIDS in Africa, has spawned a growing body of research, giving rise to a situation in which good, comparable data exist for all major regions of the world. Yet, so far, few attempts have been made to draw parallels or learn from the different experiences. (An interesting exception is a project titled 'Ageing Populations - Policy Lessons from the East' at the Institute of Applied Social Studies, Birmingham University, the results of which have just been published (Doling, Finer and Maltby 2005).) There is a growing awareness that many of the perceived differences, for example in family systems and support, pension coverage, welfare regimes and labour market patterns are exaggerated. For instance, nuclear family systems are not unique to Europe, nor is family support only important in developing countries; in the West and East the future of pension systems and ways of reaching excluded groups of older people are being discussed. The opportunity and need for comparative approaches in social research on ageing are thus manifest, and a focus on those who are most insecure and disadvantaged in old age provides an appropriate starting point. 
As the articles in this special issue illustrate, vulnerability in old age is usually the outcome of complex and cumulative processes at individual and societal levels. The various approaches to the study of vulnerability overlap with each other and with established ageing research, notably lifecourse approaches and work on quality of life, social networks, social exclusion and discrimination. The study of vulnerability therefore has the potential for interesting cross-fertilisation, theory building and interdisciplinarity in ageing research. Such considerations lie behind the idea for an international and inter-disciplinary workshop on vulnerability in old age, which in turn has given rise to the papers that are published in this special issue. The workshop, Old-age Vulnerabilities: Asian and European Perspectives, took place in Malang, Indonesia, in July 2004 and was funded by the Asia-Europe Foundation and the European Alliance for Asian Studies. It brought together anthropologists, economists, demographers, lawyers and representatives from non-governmental organisations that work with older people, and its aim was to examine the outcomes that older people feel vulnerable to, the circumstances that contribute to their vulnerability, and the coping capacities which may protect them from threats and mitigate their consequences.

The concept of vulnerability has a long history, especially in studies of natural disasters, social development, epidemiology and famine, but it has rarely been applied systematically to the study of ageing. Perceptions of older people as a 'vulnerable group' were of course common in early thinking on ageing and persist in certain stereotypical media portrayals. Most current research rightly criticises blanket assumptions of older people's dependence and vulnerability. Our intention in this special issue is certainly not to regress to a perception of older people's situation as generally or inevitably problematic, but to highlight the fact that some people face considerable insecurity and a lack of wellbeing in old age. Whilst certain risks are indisputably shaped by age, vulnerability is ultimately the product of the interplay between biological and social threats, individual characteristics and resources, social relationships and wider economic, political and cultural structures. This complexity points to a need for the methodical study of differential vulnerability in old age as a precondition for effective social policy.

Therefore, the first paper in this collection, by Schröder-Butterfill and Marianti, develops a conceptual framework for understanding vulnerability which distinguishes the different 'ingredients' of vulnerability and examines their interactions. According to this framework, a person's vulnerability is the result of the inter-related risks of being exposed to a particular threat, encountering that threat, and lacking the resources to respond in such a way as to avert serious harm. The remaining papers are 
all in one way or another concerned with identifying vulnerable older individuals or subgroups. The sources of vulnerability and the contexts differ in the different contributions, giving rise to a diverse set of case studies from Europe and Asia. Philip Kreager analyses the differential impact of migration on the support networks of older people in three rural communities in Indonesia. Peter van Eeuwijk investigates the circumstances contributing to vulnerability to failing physical and instrumental care in illness among older people living in urban areas of Sulawesi (Indonesia). The paper by Peter Lloyd-Sherlock applies a multidimensional 'asset vulnerability framework' to identify subgroups among older Thais who are economically vulnerable. Emily Grundy examines the distribution of vulnerability in Europe by analysing the distribution of older people's reserve capacities and sources of support, including their family and social networks, material resources, health status, and professional services.

Despite the diversity of cultural contexts and kinds of vulnerability covered, a number of common themes run through the papers. The first are the questions of who defines vulnerability and on what criteria. In dealing with disadvantaged or marginalised groups, who may be unable to make their needs known, there is often a tension between paternalism and individual self-determination. As Schröder-Butterfill and Marianti argue, where policy makers, professionals or researchers single out certain groups as vulnerable and in need of treatment or protection, they risk imposing standards that are not shared by the individuals in question, whilst not acting risks neglecting those who most need assistance. Definitions of vulnerability may also be contested by other, more privileged groups and thereby deprive the needy of help. Lloyd-Sherlock, for example, reports on the expansion of free health entitlement cards in Thailand, which in the past targeted people aged 6o or more years, to cover the entire population, with the result that services are now wholly inadequate.

The papers by Grundy, Lloyd-Sherlock and Kreager all point to the problems of inferring vulnerability from aggregate sources, as the meanings of apparently similar outcomes differ for different subgroups. To exemplify, Grundy shows that solitary living among older people may connote loneliness and lack of support, or may be indicative of a preference for privacy and successful independence. In Indonesia, as elsewhere in the developing world, the out-migration of young adults from rural areas is commonly interpreted pessimistically as contributing to the wholesale abandonment of older people. In fact, as Kreager is able to show, among wealthy older people migration represents part of a family strategy, but it may deprive poor older parents of important sources of support. In-depth qualitative research is arguably necessary to raise our 
understanding of what counts as good or bad outcomes. As the papers by van Eeuwijk and Kreager illustrate, vulnerability is felt by older people not just in relation to whether or not they receive support and care, but also in terms of who it is they depend on. Both the reliance on distant kin or nonkin and the inability to reciprocate have connotations of charity and pity, which in themselves represent 'bad ends'.

The second major theme that unites the collection is a concern with the disparate strategies and resources by which older people seek to reduce their vulnerability. The paper by Grundy provides a comprehensive discussion of different kinds of 'compensatory supports' that older people draw on, including state and family support, but also less commonly considered ones, such as people's management of their expectations and the 'selective optimisation' of functions, activities and contacts. All the papers draw attention to the limitations of state support in reducing older people's vulnerability. On the one hand, this reflects the papers' geographical bias: whilst in Europe the state has played an important role in reducing vulnerability to old-age poverty, in Indonesia and Thailand, like many countries of the developing world, the systems of formal social protection are inadequate, and reliance is perforce on informal networks. On the other hand, many of the vulnerabilities faced by older people, such as those surrounding intimate care, emotional support or social participation, are arguably not best addressed through formal channels but through family and community networks.

The papers by Grundy, Kreager and van Eeuwijk underline the key importance of close relatives, especially children and spouses, for the wellbeing of older people. In Europe and Asia, it is older people with small or non-existent family networks who are most vulnerable to a lack of care, a low quality of life and a bad death. There is also, however, increasing recognition of the important contributions towards protection and support in old age by more distant kin, friends, neighbours and community institutions, as reflected in several papers in this collection. Lloyd-Sherlock considers the role of funeral funds and savings co-operatives as sources of material security in Thailand, whilst van Eeuwijk points to the growing importance in urban Indonesia of support by older people's age-peers and non-relatives, which he regards as a function of population ageing and competing demands on the time and resources of young family members.

A striking finding to emerge from the papers is not only the centrality of 'coping resources' in explaining people's degree of vulnerability, but also their ability to mediate some of the social disadvantages accrued over the lifecourse. Thus the relationship between old-age vulnerability and gender is often contrary to expectations. Grundy is able to show that spouseless and/or childless men are much more vulnerable to a lack of support than 
women, as women are better able to build and maintain compensatory social networks. Men's less extensive and reliable social networks are also one reason why they are more prone to becoming homeless. In Thailand, Lloyd-Sherlock finds surprisingly few gender differences in material vulnerability, partly because men's and women's labour force participation are similar, and partly because women compensate for a lack of income through greater receipts of transfers from children. In Java, as Schröder-Butterfill and Marianti argue, older men are in a more precarious position vis-à-vis care in old age, as they depend heavily on the services of their wives or daughters, whereas older women are able to satisfy many of their instrumental needs independently.

Where gender disadvantages appear to be reversed with respect to certain old-age vulnerabilities, disadvantages on the basis of economic status seem to be more pervasive and persistent. This is partly due to the inter-relatedness of different vulnerabilities, which is a third theme common to the papers in this special issue. Thus Kreager shows how the material insecurity of certain older people in Indonesia is exacerbated, both because childlessness and small family sizes are concentrated among the poor, and because poor parents are unable to endow their children with economic opportunities, with the result that children tend also to be poor and/or to be lost to local networks due to migration. Findings pointing to the combined effects of different sources of vulnerability in Europe are presented by Grundy, who observes that older people with poor levels of social support and material wellbeing tend also to suffer from poor health and accelerated mortality. Perhaps the clearest illustration of the ways in which different individuals' vulnerabilities are mutually constituted is in van Eeuwijk's discussion of failing long-term care arrangements in urban Indonesia. He finds that as an older person becomes increasingly dependent on intensive, intimate care, this care falls disproportionately on a few female kin, often themselves already elderly or in other ways vulnerable. The result is that care becomes a burden that care-givers are increasingly unable to bear, with obvious deleterious consequences for the older people reliant on care.

In focusing primarily on vulnerability vis-à-vis old-age support and care, and on selected countries in two major regions of the world, the special issue inevitably leaves unexplored much thematic and geographical ground. It would be interesting to examine the political and legal dimensions of vulnerability, e.g. the impact of ageism or discriminatory legislation on older people's marginalisation or their ability to maintain independence. Structural and environmental influences on outcomes in old age are likely to be important, e.g. environmental degradation and economic restructuring may disproportionately affect the older 
population, both directly by depriving them of customary coping resources, and indirectly by undermining the ability of their support network members to provide assistance. Little attention has been paid here to 'emotional' vulnerabilities, as to loneliness or depression in old age. Several of the papers take a comparative approach, but much scope remains for further research that directly compares cultural or ethnic groups, countries of the North and South, or societies at different historical periods. It is hoped that readers will regard these omissions not as shortcomings of this special issue, but as an inspiration to re-examine their material in the light of the approaches introduced here and to contribute to developing our understanding of the causes and remedies of old-age vulnerability.

\section{Acknowledgements}

The guest editors express their gratitude to the Asia-Europe Foundation and the European Alliance for Asian Studies for the financial support of the workshop in Indonesia which resulted in this collection of the papers, and to all participants of the workshop for their contributions which have enriched our understanding of vulnerability in a diverse range of settings. Special thanks are due Tony Warnes for his repeated close reading and constructive criticism of the papers.

\section{Reference}

Doling, J., Finer, C. J. and Maltby, T. (eds) 2005. Ageing Matters: European Policy Lessons from the East. Institute of Applied Social Studies, University of Birmingham, Aldershot, Hampshire.

\section{ELISABETH SCHRÖDER-BUTTERFILL and RULY MARIANTI}

\section{Postscript}

The final paper in this issue, by Zheng Wu and Christoph M. Schimmele, was independently submitted.

\section{TONY WARNES}

